\title{
AS LIÇÕES \\ INOVADORAS \\ DE RUBENS DO AMARAL \\ NO TEXTO “O ENSINO DO \\ PORTUGUÊS”
}

\author{
LECCIONES INNOVADORAS DE RUBENS AMARAL EN EL TEXTO "LA ENSEÑANZA DEL \\ PORTUGUÉS"
}

RUBENS DO AMARAL'S INNOVATIVE LESSONS IN THE TEXT “PORTUGUESE TEACHING”

\author{
Criseida Rowena Zambotto de Lima* \\ SEDUC/SME - Várzea Grande/MT \\ Maria Inês Pagliarini Cox** \\ Universidade Federal do Mato Grosso
}

\begin{abstract}
RESUMO: Este estudo intenciona, a partir da proposta da linguística folk (PAVEAU, 2018), analisar o texto de Rubens do Amaral, publicado em 1939, no qual o autor antecipa em meio século a crítica à confusão entre ensino de língua e ensino de gramática, apresentando linhas mestras do novo paradigma de ensino com base no eixo uso-reflexão-uso, urdido a partir da década de 1980 pela Linguística. Compreendendo com a autora que os saberes linguísticos folk podem constituir teorias sociais da linguagem, buscamos correlacionar o discurso desse não-linguista, que produz saberes linguísticos espontâneos, a discursos provindos de conhecimentos linguísticos cientificamente validados pelas teorias linguísticas e consolidados em políticas curriculares de ensino, considerando as abordagens científica e popular como antieliminativas.
\end{abstract}

PALAVRAS-CHAVE: Rubens do Amaral. Linguística folk. Abordagem antieliminativa

RESUMEN: Este estudio pretende, al se basar en la propuesta de la lingüística folk (PAVEAU, 2018), analizar el texto de Rubens do Amaral, publicado en 1939, en el que el autor anticipa, en medio siglo, la crítica de la confusión entre la enseñanza de lengua y la enseñanza de gramática, presentando pautas del nuevo paradigma de enseñanza basado en el eje de uso-reflexión-uso, tejido desde la década de 1980 por la lingüística. Comprendiendo con la autora que el conocimiento lingüístico folk puede constituir teorías sociales del lenguaje, buscamos correlacionar el discurso de este no lingüista, que produce saber lingüístico espontáneo, con

\footnotetext{
* Criseida Rowena Zambotto de Lima é doutora pelo Programa de Pós-Graduação em Estudos de Linguagem pela Universidade Federal de Mato Grosso (2019) e professora das redes municipal e estadual de Várzea Grande/MT. E-mail: cris_zambotto@hotmail.com.

** Maria Inês Pagliarini Cox é doutora em Educação pela Universidade Estadual de Campinas (1989) e professora do Programa de Pós-Graduação em Estudos de Linguagem pela Universidade Federal de Mato Grosso. E-mail: minescox @ hotmail.com.
} 
discursos derivados de los conocimientos lingüísticos científicamente validados por teorías lingüísticas y consolidados en políticas de enseñanza curricular, considerando los enfoques científicos y populares como anti-eliminativos.

PALABRAS-CLAVE: Rubens do Amaral. Lingüística folk. Postura anti-eliminativa

ABSTRACT: This study aims, from the folk linguistics proposal (PAVEAU, 2018), to analyze Rubens do Amaral's text, published in 1939 , in which the author anticipates by half a century the criticism in relation to the confusion between language teaching and grammar teaching, presenting guidelines of the new teaching paradigm based on the use-reflection-use principle woven in the 1980s by Linguistics. Following Paveau's concept that folk linguistics knowledge may constitute social linguistic theories, we seek to correlate the discourse of this non-linguist, who produces spontaneous linguistic knowledge, to discourses derived from linguistic knowledge scientifically validated by linguistic theories and consolidated in curricular teaching policies, considering the popular and scientific approaches as anti-eliminative.

KEYWORDS: Rubens do Amaral. Folk linguistics. Anti-eliminative position.

\section{INTRODUÇÃO}

A gramática é a planta da língua, boa para consulta, imprestável para transmitir o seu conhecimento. (Rubens do Amaral, 1939)

Escrevemos este texto a quatro mãos, motivadas pela leitura de um texto que, apesar de escrito em 1939, nos causou espanto pela sua atualidade. Fazíamos uma varredura do arquivo de textos compilados por Edith Pimentel Pinto na coletânea $O$ português do Brasil, em busca de formulações acerca da colocação dos pronomes oblíquos átonos com as quais pudéssemos constituir um corpus a ser lido pelo viés da análise de discurso de base enunciativa, quando nos deparamos com o artigo O ensino do português de Rubens do Amaral. Nesse artigo, o autor criticava a confusão entre ensino de língua e ensino de gramática, reputando-o como ineficaz, posição que antecipa em meio século algumas das linhas mestras do novo paradigma de ensino, urdido na confluência de várias disciplinas da macrolinguística ${ }^{1}$ a partir da década de 1980. De pronto, o texto de Amaral nos remeteu ao livro do linguista Sírio Possenti Por que (não) ensinar gramática na escola, publicado na década de 1990, com uma crítica contundente ao ensino da língua reduzido ao repasse de uma teoria gramatical prescritiva, sem qualquer vínculo com atividades efetivas de leitura e escrita.

Rubens do Amaral (1890-1964) é um paulista, nascido na cidade São Carlos. Foi jornalista e escritor. Desempenhou a função de jornalista no Diário da Noite, no Diário de São Paulo, na Folha da Manhã e no Correio de São Paulo. Foi, primeiro, deputado do estado de São Paulo e, depois, vereador na cidade de São Paulo por várias legislaturas. Escreveu vários livros: União Soviética Inferno ou Paraiso? (1953), Os Cristãos e o Problema da Terra (1956), Terra Roxa (1934), Luzes do Planalto (1962) e A Campanha Liberal (1930), ocupando a cadeira 9 da Academia Paulista de Letras em cuja revista foi originalmente publicado o texto que nos chamou a atenção e nos instigou a escrever este artigo em que fazemos um contraponto entre as linhas do novo paradigma de ensino de língua, estabelecidas e oficializadas pelos PCNs em 1998, e as defendidas por Rubens do Amaral em 1939.

\section{AS LIÇÕES DO NOVO PARADIGMA DE ENSINO}

Embora mais de trinta anos separem a história de escolaridade das duas autoras deste artigo, pouca coisa mudou no ensino de português que cada uma delas vivenciou como aluna até chegar à universidade e entrar em contato com a linguística. De origem rural, viram a língua que aprenderam nas interações com a família, os amigos e nos círculos de convivência mais próximos ser

\footnotetext{
${ }^{1}$ Bárbara Weedwood (2002, p. 11) distingue a microlinguística (fonologia, morfologia, sintaxe, lexicologia e semântica) da macrolinguística (sociolinguística, pragmática, psicolinguística, análise de discurso, análise da conversação, linguística do texto etc.). É sobre uma base sólida de conhecimentos produzidos no âmbito da macrolinguística que o novo paradigma de ensino-aprendizagem de língua materna foi erigido.
} 
desqualificada e avaliada como "errada" nas aulas de gramática que reduziam o português à norma-padrão. Com essa prática, cresceram pensando não saber português e se sentindo inseguras e hesitantes toda vez que tinham de usar a língua em situação pública, fora do nicho familiar. Contudo, ao chegarem ao curso de Letras e entrarem em contato com a Linguística, uma disciplina anunciada como produtora de conhecimentos científicos acerca das línguas, suas visões e atitudes em relação ao português e ao seu ensino, começaram a mudar. O contato com a Linguística lhes permitia compreender e lidar consciente e emancipadamente com o estigma e o preconceito que maculavam sua variante linguística materna no espaço escolar.

Em contato com a Linguística, aprenderam que o português não se reduz à norma-padrão, que o português, como qualquer outra língua viva, é um conjunto de variedades, ou seja, que "o português são muitos portugueses" (FARACO, 2008, p. 5); que as línguas são primeiro faladas e depois escritas (e nem todas o são), de modo que a escrita não deve ser tomada como modelo para a fala; que as línguas variam e mudam incessantemente; que variar e mudar não significa se deteriorar e sim se diferençar (ZILES, 2008); que dominar conhecimentos gramaticais formalizados e nomenclaturizados não é condição ou garantia para o uso adequado da língua nas mais diversas circunstâncias e muitas outras coisas aprenderam com a linguística que as fez desconfiar do ensino gramatical e iniciar um processo de reconstrução de suas próprias práticas como professoras, concomitantemente com a fermentação, nas décadas de 1980 e 1990, de um novo paradigma de ensino de português, fundamentado em disciplinas linguísticas, que culminou com a publicação dos PCNs em 1998.

A Linguística passou a integrar timidamente o currículo dos cursos de Letras na década de 1960, contemplando, num primeiro momento, disciplinas do núcleo duro como fonologia, morfologia, sintaxe, etc. Esses ramos da chamada Linguística imanente ou microlinguística, por se concentrarem na descrição e análise sistêmica da língua, não instigaram uma revolução no paradigma tradicional de ensino do português nucleado pelos princípios da chamada gramática normativa.

Contudo, ainda nesse período, a macrolinguística brasileira, seguindo a tendência americana e francesa, se expandia enormemente, abeirando objetos que extrapolavam o nível da frase e/ou faziam interface com outras disciplinas como sociologia, psicologia, psicanálise, etnologia, história, dentre outras. Ramos da linguística como sociolinguística, psicolinguística, linguística textual, análise de discurso, análise da conversação, pragmática e linguística aplicada se desenvolveram rapidamente, resultando em um crescimento extraordinário dos programas de pós-graduação stricto sensu em linguística e, em consequência, das pesquisas na área, nas universidades brasileiras.

Indagada sobre sua utilidade, como é de praxe nas sociedades sob a égide do capitalismo, que avalia como inútil a chamada ciência básica e desinteressada, a Linguística se apresenta como uma disciplina que teria muito a dizer sobre o ensino-aprendizagem de línguas. Entre as universidades brasileiras com programas de pós-graduação em linguística, é a UNICAMP² que deflagra e propaga as ideias seminais do novo paradigma de ensino de língua portuguesa, propondo uma inversão radical do eixo reflexão-uso para o eixo uso-reflexão-uso.

Essa inversão propunha o fim da hegemonia do ensino gramatical sobre a norma-padrão escrita, desacreditando-o como uma via segura para habilitar os alunos ao uso adequado da língua nas mais diversas situações. O eixo do uso inclui tanto a oralidade quanto a escrita, aquela compreendendo "práticas de escuta e produção de textos orais" e essa compreendendo "práticas de leitura e produção de textos escritos". A reflexão, por sua vez, passa a se subordinar ao uso da língua, acionada sempre que se mostrar relevante ao aperfeiçoamento das práticas de escuta, leitura e produção de textos orais e escritos.

Não demorou para que esse novo paradigma em germinação nas universidades e intensamente divulgado por meio de eventos e publicações da área passasse a interessar instâncias educacionais governamentais em nível municipal, estadual e federal que buscavam soluções para o colossal problema do fracasso escolar, impossível de ser varrido para debaixo do tapete, desde o processo de democratização do acesso à escola pública na década de $1960^{3}$. O problema era grande demais para não ser visto. Havia uma

\footnotetext{
${ }^{2}$ O professor João Wanderley Geraldi capitaneou, a partir da UNICAMP, o movimento de mudança de paradigma do ensino de língua portuguesa.

${ }^{3}$ A Lei nº 4.024, Lei de Diretrizes e Bases da Educação, aprovada em 1961, estabeleceu, em seu art. 2º que "A educação é direitos de todos e será dada no lar e na escola”.
} 
gritaria geral, na escola e fora da escola, acerca de uma suposta crise da leitura e da escrita que afetava o desempenho dos alunos em todas as matérias e contava entre os fatores que levavam ao fracasso escolar como um todo. Essa crise ganhou grande repercussão na mídia por ocasião do primeiro vestibular unificado da FUVEST (1977) que incluía USP, UNICAMP, UNESP e escolas do interior. As milhares de redações juntas impressionavam e causavam escândalo não pelo bom desempenho dos vestibulandos na escrita, mas por suas "pérolas".

Assim, um paradigma que prometia resolver a crise da leitura e da escrita caía como uma luva naquele contexto profundamente modificado da escola pública que, após a democratização, recebia uma população bastante heterogênea, falando portugueses bem diferentes daquele ensinado nas aulas de língua. Os portugueses adquiridos, como língua materna, nos processos de socialização primária eram tão desiguais do português ensinado na escola que esse mais se assemelhava a uma língua estrangeira. As aulas de gramática da norma-padrão que, supostamente, haviam dado certo no passado, quando a escola pública abrigava principalmente os filhos da elite, mostravam-se inócuas para ensinar os filhos das classes populares a usar uma língua com que não tinham nenhuma familiaridade. Universalizado o acesso à escola pública, era, pois, sentida a necessidade de se encontrar um modelo adequado de educação para um universo de crianças, jovens e adultos com perfil sócio-econômico-cultural diverso daquele legitimado pelos conteúdos até então constantes das matérias curriculares.

Esse modelo seria o de uma pedagogia culturalmente sensível que trabalha a língua como um conjunto de variedades e rejeita preconceitos linguísticos, entendendo que é papel da escola, conforme Bortoni-Ricardo (2004, p. 74), "[...] facilitar a ampliação da competência comunicativa dos alunos, permitindo-lhes apropriarem-se dos recursos comunicativos necessários para se desempenharem bem nas mais distintas tarefas linguísticas".

Reconhecendo e respeitando os portugueses que os alunos trazem à escola como línguas boas, cabe à educação formal potencializar seus repertórios, assegurando que aprendam principalmente as variedades cultas do português brasileiro, necessárias para o exercício da vida profissional e para as interações sociais mais protocolares. Desse modo, a pedagogia culturalmente sensível foi sentida como viável, por órgãos ligados ao Ministério de Educação e Cultura, para lidar positivamente com a heterogeneidade linguística presente na escola pública, sem rejeitá-la, silenciá-la ou discriminá-la.

Equipes multidisciplinares de educadores, com a participação de linguistas que vinham insistindo na necessidade de renovação do paradigma do ensino de língua, foram constituídas pelo MEC, na segunda metade da década de 1990, com a tarefa de propor parâmetros curriculares que, de um lado, "[...] respeita[ssem] diversidades regionais, culturais, políticas existentes no país e, de outro, considera[ssem] a necessidade de construir referências nacionais comuns ao processo educativo em todas as regiões brasileiras." (BRASIL/PCNs, 1998, p. 05), promovendo uma educação comprometida com a formação cidadã dos alunos em todos os níveis da escola básica.

Diante desse princípio, o paradigma tradicional de ensino da língua portuguesa é criticado pelos PCNs (BRASIL, 1998, p. 18) por desconsiderar a realidade e os interesses dos alunos; por escolarizar excessivamente as atividades de leitura e produção de texto; por usar "[...] o texto como expediente para ensinar valores morais e como pretexto para o tratamento de aspectos gramaticais"; por valorizar excessivamente "a gramática normativa e insistir nas regras de exceção, com o consequente preconceito contra as formas de oralidade e as variedades não-padrão"; por promover "o ensino descontextualizado da metalinguagem, normalmente associado a exercícios mecânicos de identificação de fragmentos linguísticos em frases soltas"; por apresentar "uma teoria gramatical inconsistente, uma espécie de gramática tradicional mitigada e facilitada”.

Em resposta a essas críticas, segundo os PCNs (1998, p. 18) "as propostas de transformação do ensino de Língua Portuguesa consolidaram-se em práticas de ensino em que tanto o ponto de partida quanto o ponto de chegada é o uso da linguagem”. Por isso, o objetivo que abre a lista é

\footnotetext{
${ }^{4}$ Hoje, a mídia se farta com as "pérolas" do ENEM.
} 
[...] utilizar a linguagem na escuta e produção de textos orais e na leitura e produção de textos escritos de modo a atender a múltiplas demandas sociais, responder a diferentes propósitos comunicativos e expressivos, e considerar as diferentes condições de produção do discurso. (BRASIL, 1998, p. 32)

Para perseguir esse objetivo, a escola precisa efetivamente trabalhar com o uso da língua e não com sua gramática. O que isso significava em termos de mudança curricular? Significava fazer das aulas de língua portuguesa não mais aulas de estrutura, nomenclaturas e prescrições gramaticais, baseadas em frases soltas, e sim aulas de prática de recepção e produção de gêneros discursivos orais e escritos, levados para a sala por meios de textos que os representem. A recepção dos gêneros (escuta e leitura) deve ser trabalhada na perspectiva da compreensão ativa e não da mera decodificação e do silêncio e a produção de textos orais e escritos deve visar à interação efetiva e não à mera correção.

Como os gêneros discursivos se caracterizam pela diversidade de expressão, o trabalho pedagógico com eles permite "conhecer e valorizar as diferentes variedades do português, procurando combater o preconceito linguístico” (BRASIL1998, p. 33). Permite ainda a cada aluno

[...]reconhecer e valorizar a linguagem de seu grupo social como instrumento adequado e eficiente na comunicação cotidiana, na elaboração artística e mesmo nas interações com pessoas de outros grupos sociais que se expressem por meio de outras variedades. (BRASIL1998, p. 33)

O estigma e o preconceito linguístico com que a escola macula as línguas maternas de seus alunos costumam abrir feridas identitárias dolorosas que jamais se cicatrizam.

Até toparmos casualmente com o texto de Rubens do Amaral, pensávamos que a reordenação dos eixos do ensino de língua portuguesa de reflexão-uso para uso-reflexão-uso era fruto do que as disciplinas macrolinguísticas nos ensinaram e os PCNs endossaram, mas não...

\section{AS LIÇÕES DE RUBENS DO AMARAL}

O texto O ensino do português, de Rubens do Amaral, é representativo de um grupo de textos produzidos antes da institucionalização da chamada linguística moderna no Brasil ${ }^{5}$, na década de 1960, mas que ficaram no limbo, toldados pela voz dominante da tradição gramatical no período, que silenciava toda sorte de reflexão sobre a língua e seu ensino que se desviasse da rota habitual que ia da gramática para a língua.

Ante a constatação da falência do ensino do português à época, Rubens do Amaral propunha uma inversão da rota - ir da língua para a gramática, uma vez que a primazia da gramática não resultava em aprendizagem satisfatória: primeiro porque era um equívoco tomar a gramática como sinônimo de língua e, segundo, porque a gramática ensinada na escola sequer correspondia à da língua daqueles que eram submetidos a seu ensino.

Assim como os precursores do novo paradigma de ensino, no final da década de 1970, também Rubens do Amaral foi tocado pelo clamor público generalizado acerca do desempenho aquém do desejável evidenciado por aqueles que realizavam exames oficiais, como o de madureza ${ }^{6}$ e o de vestibular da USP. Nos exames de madureza aplicados nos ginásios oficiais, a taxa de reprovação atingiu 90\%, resultado que, segundo o autor, provocou "verdadeiras hecatombes". E, nesse fracasso retumbante, o português entrava com uma "altíssima porcentagem":

\footnotetext{
${ }^{5}$ A chamada linguística moderna rompeu com a tradição filológica, historicista e normativa, enfatizando a descrição sincrônica das línguas em funcionamento. Segundo Altman (2009, p. 127), na década de 1960, estabelecia-se no Brasil, uma equivalência “entre 'Linguística' e 'descrição sincrônica' [...] uma vez que a recepção/divulgação do termo Linguística coincidiu com a recepção do estruturalismo (tanto descritivista quanto funcionalista)”.

${ }^{6}$ Oliveira (2017) esclarece que, devido ao fenômeno de industrialização e urbanização, havia a necessidade de expansão quantitativa de ensino. Desse modo, a reforma de Francisco Campos (1932) introduziu o exame de madureza como certificação do "ginásio" (Fundamental) e "secundário" (Ensino Médio).
} 
Recrudesce por aí, atualmente, o clamor contra as deficiências do ensino do português. O imprevisto dos exames de madureza prestados obrigatoriamente nos ginásios oficiais ocasionou verdadeiras hecatombes; as reprovações atingiram a 90\% na capital de S. Paulo; e o português entrou com altíssima porcentagem nesses fracassos. Findos os exames vestibulares da Universidade Paulista, houve quem declarasse que, se existisse rigor quanto à língua, as nossas escolas superiores ficariam vazias e teriam de fechar as portas. [...] E tudo atesta que os brasileiros, em geral, não sabem português. (AMARAL, 1981 [1939], p. 417)

Amaral antecipou em algumas décadas a necessidade de atacar a famigerada crise da leitura e escrita, responsabilizada pelo fracasso escolar como um todo, mas não foi ouvido. Essa crise continua gerando preocupação aos órgãos educacionais e clamor generalizado na mídia que se compraz em expor o pífio desempenho dos alunos toda vez que são divulgados resultados de exames como IDEB (Índice de Desenvolvimento da Educação Básica); Pisa (Programme for International Student Assessment) e Enem. Ainda hoje esses resultados são usados como justificativa para sentenciar o brasileiro como alguém que "não sabe o português", "não sabe ler", "não sabe escrever".

A solução para o problema, apontada por contemporâneos de Rubens de Amaral que se escandalizaram com a taxa de reprovação nos exames oficiais, era o aumento da carga horária da disciplina de língua portuguesa, quer dizer, os alunos precisavam de aulas de gramática diariamente ao longo de todo o percurso escolar:

O remédio? O que vemos por aí proposto é que se multipliquem as aulas de português, colocando-as diárias nos cursos ginasiais e nos cursos complementares, os chamados "pré", para que a juventude aprenda a língua durante sete anos a fio, quotidianamente. (AMARAL, 1981 [1939], p. 417)

Segundo Amaral, é um equívoco administrar mais aulas de português, se elas forem maciçamente aulas de gramática. A seu ver não é a falta de aulas de gramática a responsável pelo fracasso dos alunos, e sim a concepção mesma de que o domínio da teoria gramatical e do códice normativo leva ao domínio da língua. Para o autor (1981 [1939], p. 419.), se os alunos, submetidos ao ensino gramatical, não aprendem uma língua em até "dois ou até três anos", não será fazendo mais do mesmo, ao longo de mais tempo, que se tornarão proficientes, como se pudesse ser certo que quem não aprende uma língua em dois ou três anos seja capaz de aprendê-la durante o resto da vida! (AMARAL, 1981 [1939], p. 417)

O fracasso, segundo Amaral, estaria localizado na confusão reinante entre língua e gramática e o consequente currículo inspirado numa visão retórico-gramatical da cultura humanística, centrado no repasse de uma certa metalinguagem que assusta até pela esquisitice dos termos:

No entanto, eu estou convencido de que isso não adiantaria coisa nenhuma, por esta razão audaciosa, mas profundamente verdadeira: o que se ensina por aí não é a língua, é a gramática, coisa muito diferente... Os meninos passam meses e anos a lidar com uns abantesmas que atestam o pedantismo e o mau gosto dos gramáticos: taxonomia, proparoxítonas, aférese, apócope, ênclise, próclise, silepse, anacoluto, metátese, tmese, hipérbaton, anástrofe, sínquise, epêntese, paragoge, eclipse ... E têm que classificar os advérbios, as conjunções, as preposições, ninguém sabe para que fim útil. E têm que perder tempo e fósforo, nas celebérrimas análises lógicas, a que os professores se entregam com sádico prazer, em sutilezas bizantinas e em torturas chinesas, escusadíssimas porque conheço muita gente que escreve bem sem saber análise e muita gente que sabe análise e não escreve aceitavelmente. (AMARAL, 1981 [1939], p. 417)

Amaral realiza uma crítica mordaz à concepção de que ensinar gramática é ensinar língua. Para ele, são coisas muito diferentes. Os alunos podem dominar todas as regras e as esdrúxulas taxionomias gramaticais, sem que isso resulte em bom desempenho de leitura e escrita. $\mathrm{O}$ autor considera que esse modo de conduzir o ensino-aprendizagem da língua é perda de tempo e desgaste inútil de fósforo. O uso efetivo da língua escrita não decorre de um aprendizado passivo dos conhecimentos compendiados nas chamadas gramáticas normativas, mas sim da inserção do sujeito em práticas de letramento.

Para Amaral, o "método" gramatical só se prestava a assombrar os alunos com "abantesmas" (fantasmas) que lhes rondavam durante os longos anos de escolarização, sem que resultasse em "aprendizagem" da língua. Arremata seu argumento afirmando que conhece 
muita gente que domina a gramática e não escreve nada, assim como conhece muita gente que não sabe nada de gramática e escreve bem, golpeando a relação de causa e efeito entre saber gramática e escrever bem.

Entre os precursores do novo paradigma de ensino de língua portuguesa, a confusão nefasta entre gramática e língua foi constantemente reiterada. Faraco (1984, p. 20) a nomeou como uma das "sete pragas do ensino do português": "o aluno é capaz de passar onze anos sem manter contato direto com a língua em si. O que lhe oferecemos é apenas metalinguagem (conceitos, regras, exceções) na ilusória certeza de estarmos ensinando a língua”. Submetido a essa confusão, o aluno não aprende nem a teoria gramatical e nem a língua, mas fica inibido para se exprimir e se comunicar ao longo de toda a vida de tanto ouvir que está errado e ser corrigido. Segundo Bagno (2003, p. 21), a equivalência língua = gramática é "parte integrante das crenças e superstições que circulam na sociedade".

Assim, a metáfora da gramática como a "planta da língua”, proposta por Rubens do Amaral no excerto seguinte, resistiu ao tempo e é de uma atualidade ímpar:

As pobres crianças empanturram-se de regras, que lhes atravancam o cérebro, como a um baú de turco, e, ao cabo de cinco, de sete anos de trabalhos e sacrifícios, não sabem falar, não sabem escrever, não sabem redigir, não sabem pensar ou traduzir o seu pensamento com ordem, clareza e elegância. É porque os professores de português procedem exatamente como um pai tonto que, devendo mandar o filho para o Rio ou S. Paulo, comprasse uma planta dessas cidades e se pusesse a ensiná-la ao rapaz. O desgraçado teria que decorar a localização de toas as ruas e praças das metrópoles, nelas situando os principais edifícios públicos, as estações ferroviárias, as casas comerciais, as linhas de bonde e onibus, as ladeiras e os morros, os mil e um acidentes naturais ou artificiais. Ao cabo de cinco, de sete anos, o rapaz nada saberia do Rio ou S. Paulo. Mas em poucas semanas de passeio, vendo, observando e anotando, poderia ser um guia em qualquer das duas cidades. $A$ gramática é a planta da língua, boa para consulta, imprestável para transmitir o seu conhecimento. E os moços brasileiros, em vez de estudar a língua, estão sendo forçados a encaixar no cérebro a planta, que os martiriza e que odeiam. (AMARAL, 1981 [1939], p. 418)

Por meio dessa metáfora, o autor critica duramente os modos pelos quais a cultura escolar mantém em seu currículo a interpretação de que ensinar a língua é ensinar sua gramática (estrutura e nomenclatura). Amaral compara a língua à cidade e argumenta que não há outro modo de um sujeito conhecê-la de fato, senão circulando por seus espaços, vivendo, observando, refletindo sobre toda a diversidade de elementos que a compõem e interagindo com outros tantos sujeitos que também nela vivem.

Porém, na escola, o professor como um "pai tonto", ao invés de circular pela língua viva, apresenta ao aluno sua planta, ou seja, a gramática. Anos a fio debruçado sobre a planta e supliciado como seus detalhes, o aluno pouco avança no domínio e na conquista da cidade. Estudar a planta de uma cidade não é um bom método para nela se mover com autonomia, assim como estudar a gramática não é um bom método para se mover pela língua, lendo e escrevendo. Com uma lucidez invejável, o autor arremata sua comparação da gramática como uma planta da língua, alertando-nos de que ela é "boa para consulta”, mas "imprestável para transmitir o seu conhecimento".

Assim, o "remédio" para o problema do ensino do português, para Amaral, não é aumentar a dose de aulas de gramática e sim remodelar o método, enfatizando a prática da língua:

O ensino do português precisa ser remodelado radicalmente, não tanto nos programas, mas principalmente nos métodos. Ensine-se a falar, a escrever, não a analisar, a classificar, a dissecar, a gramaticar. A gramática veio depois da língua e não pode antecedê-la nos estudos: fique, melhor, para curiosidade e divertimento dos que nasceram com alma de arqueólogos ou naturalistas e se meteram transviados a lecionar português. Há crianças de seis, oito, dez anos, que se exprimem perfeitamente, sem nunca terem ouvido referências às regras gramaticais e aos mais aparelhos de suplício inventados para massacrar a juventude com perfeito ausência de qualquer proveito. (AMARAL, 1981 [1939], p. 418) 
Há muita ressonância entre o que Rubens do Amaral defendia, em 1939, como método a ser seguido no ensino do português e o que o novo paradigma de ensino, oficializado pelos PCNS (1998), hoje defende. Cada um à sua maneira coloca o uso da língua no centro das atividades de ensino, destinando aos conhecimentos gramaticais um papel de coadjuvante. Em Amaral, usar a língua significa "falar" e "escrever" e não "analisar", "classificar", "dissecar" ou "gramaticar", esse último um neologismo perfeito para exprimir o que a escola tem feito com o ensino do português - na escola, os alunos "gramaticam" e não usam a língua. Nos PCNs (1998, p. 35), usar a língua significa praticar "a escuta” e "a produção de textos orais" e "a leitura” e "a produção de textos escritos".

Enfim, o método a ser usado na escola deve imitar o que ocorre na vida prática, em que se aprende a falar, ouvindo e falando, interagindo. Isso vale também para o domínio da escrita: "Como aprendemos a falar? Falando e ouvindo. Como aprenderemos a escrever? Escrevendo e lendo, e sendo corrigidos, e reescrevendo, e tendo nossos textos lidos e comentados muitas vezes, com uma frequência semelhante à frequência da fala e das correções da fala” (POSSENTI, 1996, p. 48). Na vida prática, ninguém recebe aulas de gramática para falar. Como afirma Amaral, crianças muito novas "se exprimem perfeitamente" sem nunca terem sido submetidas “às regras gramaticais e aos mais aparelhos de suplício inventados para massacrar a juventude”. É esse método que a escola deve seguir, se quiser fazer dos alunos "leitores e escrevinhadores sem traumas”. Fará isso se não os “atrapalhar" e os "entupir de exercícios sem sentido" (POSSENTI, 1996, p. 49).

Além do método, Rubens do Amaral também lembra que a dificuldade apresentada pelo aluno brasileiro em relação ao domínio da língua escrita pode estar relacionada com o fato de ele falar, na vida real, uma língua brasileira e ser submetido, na escola, à gramática da língua portuguesa:

Todavia, não esqueçamos uma questão essencial: jamais falaremos ou escreveremos bem a nossa língua enquanto não fundarmos a língua brasileira, com suas próprias regras. Qualquer português analfabeto joga perfeitamente com os pronomes oblíquos ou com o infinito impessoal, por uma razão simples: ele criou a sua língua e dela os gramáticos extraíram a gramática. Aqui, ao contrário, a língua brasileira ainda está nascendo e já querem que ela se conforme com a gramática ... portuguesa. (AMARAL, 1981 [1939], p. 418-419)

Amaral defende a necessidade de gramatizar a língua brasileira, uma língua que ainda estava nascendo. Essa gramatização deveria seguir os mesmos passos da construção da gramática do português lusitano. O povo português criou a língua, cuja gramática foi, $a$ posteriori, sistematizada pelos gramáticos. O mesmo deveria ocorrer com a língua brasileira: o povo teria de criá-la primeiro para que os gramáticos dela extraíssem sua gramática. Contudo, essa ordem natural era atropelada porque à língua que estava nascendo se impunha a gramática portuguesa. Por isso, a aprendizagem da língua era/é tão complicada para o brasileiro, as regras portuguesas contrariavam/contrariam a tendência brasileira, numa queda de braços entre o normal (seu hábito) e o normativo (imposição alheia ao hábito).

A partir dessa distinção entre normativo/normal, podemos compreender a complexidade do caso brasileiro, no qual a normapadrão se distancia inclusive da norma culta que identifica os segmentos sociais mais letrados, em determinadas situações e em práticas mais monitoradas de fala e escrita. Amaral, em defesa da emancipação da "língua brasileira”, trabalha com uma concepção descritiva, e não prescritiva, de gramática, muito antes de o estruturalismo ter se constituído e de a sociolinguística ratificar a existência de uma outra norma em nosso país.

Como assinala Bagno (2011), precisamos tomar como parâmetro uma norma urbana culta real, “uma norma que já existe, 'tácita e recalcada', e que tem de ser legitimada para que o Brasil exorcize de vez o fantasma colonial que ainda assombra nossas concepções de língua e ensino" (BAGNO, 2011, p. 27) e não "a norma padrão clássica, ideal, prescritiva e totalmente desvinculada dos usos autênticos do PB" (BAGNO, 2011, p. 21). O posicionamento de Amaral, em termos de língua, antecipa em muitas décadas a defesa, por (socio)linguistas, da existência de uma língua/norma culta brasileira apartada de Portugal. correndo novamente à metáfora da planta da cidade, Amaral fala do absurdo que é sobrepor a gramática da língua lusitana à língua brasileira:

É como tomasse uma planta de Lisboa e se quisesse aplicá-la ao Rio de Janeiro, ainda por cima declarando que a nossa Capital Federal está errada porque o traçado das ruas não confere com o da cidade de mármore e granito. A aplicação é absurda e louca é a conclusão. Mas não se está fazendo outra coisa. E, depois, admiramo-nos de 
que os brasileiros ignorem o português, ao ponto de alarmar autoridades e de se pedir que os cursos (sem contar a escola primária) se estendam por sete anos ininterruptos, em aulas diárias. (AMARAL, 1981 [1939], p. 419)

Se não podemos superpor a planta de uma cidade à outra, decretar que o traçado das ruas do Rio de Janeiro está errado porque "não confere com o da cidade de mármore e granito", também não podemos submeter a língua brasileira que está nascendo à gramática de outra língua. Esse descompasso insano entre a planta/gramática que se ensina na escola - a planta/gramática lusitana - e a cidade/língua brasileira dos alunos é uma das razões que levam à afirmação de que os brasileiros não sabem português. É, pois, o desencontro entre a língua (brasileira) e a gramática (lusitana) que leva a avaliações tão negativas dos nossos alunos.

\section{CONSIDERAÇÕES FINAIS}

Por que só por acaso, tivemos o prazer de ler um texto como esse de Rubens do Amaral? Por que ele ficou esquecido no arquivo das coisas ditas sobre a língua, até ser pinçado por Edith Pimentel Pinto para compor o segundo tomo da Coletânea $O$ português do Brasil: textos críticos e teóricos que cobre o período de 1920 a 1945 ?

A primeira hipótese que excogitamos é a de que, sendo Rubens do Amaral uma voz insurgente contra a tradição gramatical, hegemônica e praticamente sem dissidência à época, não havia razão para ser levado a sério. Era só mais um brasileiro que se rebelava contra a gramática lusitana por não dominá-la e, por isso, não era digno de crédito.

A segunda hipótese, excogitada na companhia de Altman (2009), é que a insistente retórica de ruptura, feita pela linguística, quando chegou ao Brasil, contribuiu para uma atitude de certa arrogância frente aos conhecimentos sobre a língua produzidos antes desse período "verdadeiramente científico". É como se a linguística jogasse no limbo, os saberes produzidos por não-linguistas. Enfeixados sob o rótulo de pré-científicos, foram descartados inclusive do horizonte de retrospecção de quem escrevia a história da linguística brasileira.

A primeira e a segunda hipótese lançam Rubens do Amaral num vácuo, a primeira como não-gramático e a segunda como nãolinguista. Com isso, seu texto é completamente ignorado e não provoca mudança alguma naqueles que ensinavam/ensinam a língua, a contar pelo contínuo fracasso escolar.

Contudo, a linguística começa fazer uma espécie de mea culpa, retomando o estudo de conhecimentos linguísticos eclipsados por uma concepção restritiva de ciência. Nesse sentido, Paveau (2018) assevera

A existência de um conjunto de práticas linguísticas designáveis como "folk" (ou melhor, por todo outro adjetivo estabilizado que compartilhe o mesmo domínio, como profanas, espontâneas, selvagens, ingênuas, leigas) não deixa, praticamente, nenhuma dúvida, e um campo de investigação particularmente rico se abriu para os linguistas que se preocupam com quaisquer produções imaginárias e representacionais dos falantes. (PAVEAU, 2018, p. 23).

Entendemos, com Marie-Anne Paveau (2018), que esses saberes não estão em contradição com a linguística acadêmica e podem, desse modo, serem plenamente integrados a um estudo científico da linguagem, por meio de uma abordagem integrativa na qual os conhecimentos científicos e os populares sejam antieliminativos. Os saberes dos não-linguistas são saberes legítimos e reconhecíveis como tais, o que possibilita que, ao lermos um texto como o de Rubens do Amaral, vejamos nele a germinação de um pensamento inovador em relação ao ensino da língua que já vinha sendo construído, antes mesmo de as disciplinas da macrolinguística inspirarem a proposição do novo paradigma que culminou com a proposição dos PCNs (1998).

Será que, integrando lições como as de Rubens do Amaral com lições do novo paradigma de ensino de língua portuguesa, conseguiremos superar a confusão entre a planta e a cidade, ou seja, entre a gramática e a língua? Ainda estamos longe da cidade.. 


\section{REFERÊNCIAS}

AMARAL, R. O ensino do português. In: PINTO, E. P. (org.). O português do Brasil: textos críticos e teóricos II - 1920-1945: Fontes para a teoria e a história. São Paulo: Edusp, 1981. p. 415-421.

ALTMAN, C. Retrospectivas e perspectivas da historiografia linguística no Brasil. Revista Argentina de Historiografia Linguística. 2009. p. 115-136.

BAGNO, M. Gramática pedagógica do português brasileiro. São Paulo: Parábola Editorial, 2011.

BAGNO, M. A norma oculta: língua e poder na sociedade brasileira. São Paulo, Parábola Editorial, 2003.

BORTONI-RICARDO, S. M. Educação em língua materna: a sociolinguística na sala de aula. São Paulo: Parábola, 2004.

BRASIL. Lei $n^{\circ}$ 4.024, de 20 de dezembro de 1961 (Lei de Diretrizes e Bases da Educação). Disponível em: http://www.planalto.gov.br/ccivil 03/leis/l4024.htm. Acesso em: 22 ago. 2019.

BRASIL. Parâmetros Curriculares Nacionais: terceiro e quarto ciclos do ensino fundamental - língua portuguesa. Brasília: MEC/SEF, 1998.

FARACO, C. A. Português: um nome, muitas línguas. (Programa Salto para o Futuro) Boletim 08, Ano XVIII, maio de 2008. p. 0311.

FARACO, C. A. As sete pragas do ensino de português. In: GERALDI, J. W. O texto na sala de aula: leitura \& produção. Cascavel: Assoeste, 1984.

OLIVEIRA. K. R. V. . Exames de madureza em Mato Grosso: 1930 - 1970. 2017. 96f. Dissertação (Mestrado) - Programa de Pósgraduação em Educação, Instituto de Educação da Universidade Federal de Mato Grosso, 2017.

PAVEAU, Me. Não linguistas fazem linguística? Uma abordagem antieliminativa das ideias populares. Policromias - Revista de Estudos do Discurso, Imagem e Som [Online], v.3. n.2, p. 21-45, 2018.

PINTO, E. P. (org.). O português do Brasil: textos críticos e teóricos I - 1820-1920: Fontes para a teoria e a história. São Paulo: Edusp, 1978. 
PINTO, E. P. (org.). O português do Brasil: textos críticos e teóricos II - 1920-1945: Fontes para a teoria e a história. São Paulo: Edusp, 1981.

POSSENTI, S. Por que (não) ensinar gramática na escola. Campinas: Mercado de Letras/ALB, 1996.

WEEDWOOD, B. História concisa da linguística. São Paulo: Parábola, 2002.

ZILES, A. M. S. Variação no português falado e escrito no Brasil. (Programa Salto para o Futuro) Boletim 08, Ano XVIII, , p. 38-54, maio 2008.

\section{(ㅇ) (1) $\odot \odot$}

Recebido em 04/09/2019. Aceito em 16/10/2019. 